\title{
Social, economic, and legislative factors and global road traffic fatalities
}

\author{
Mohammad Reza Rahmanian Haghighi, Mohammad Sayari, Sulmaz Ghahramani and Kamran Bagheri Lankarani*
}

\begin{abstract}
Background: Road traffic fatalities (RTF) is the 8th cause of mortality around the world. At the end of the Decade of Action, it would be of utmost importance to revisit our knowledge on the determinants of RTF. The aim of this study is to assess factors related to RTF at global level.

Methods: We used road safety development index which accounts for the interactions between system, human and products to assess the RTF in 115 and 113 countries in 2013 and 2016, respectively. To analyze data, three statistical procedures (linear regression, classification and regression trees, and multivariate adaptive regression splines) were employed.

Results: Classification and regression trees has the best performance amongst all others followed by multivariate adaptive regression splines for 2013 and 2016 data set with an $R^{2}$ around 0.83 . Results show that any increase in human development index was associated with RTF reduction. Comparing RTF data of 2013 and 2016, 8 countries experienced a change of more than 30\%, which demonstrated a significant relationship with GINI index (named after Corrado Gini). Considering the three components of human development index, it is revealed that education explained most of RTF variation in classification and regression trees model followed by income and life expectancy.

Conclusion: Policymakers should consider road collisions as a socio-economic issue. In this regard, they can make provisions to reduce RTF in the long run by focusing on enhancing the three components of human development index, mainly education. However, there is a need to investigate the causation pathway among these three components with RTF with different time-trend procedures.
\end{abstract}

Keywords: Human development index, Education, Income, Life expectancy, GINI index, Road traffic fatalities

\section{Background}

According to recent World Health Organization (WHO) reports, road traffic fatality (RTF) was the 8th leading cause of death worldwide in 2016 [1]. In this year, approximately 1.35 million people were killed in road collision. Based on WHO's report (2018), A total of $40 \%$ of motorized vehicle are registered in high-income countries (with Gross National Income (GNI) per capita of more than 12,235 current US dollar), but only $7 \%$ of RTF has

\footnotetext{
* Correspondence: kblankarani@yahoo.com

Health Policy Research Center, Institute of Health, Shiraz University of Medical Sciences, Shiraz, Iran
} $\triangle B M C$

(c) The Author(s). 2020 Open Access This article is licensed under a Creative Commons Attribution 4.0 International License, which permits use, sharing, adaptation, distribution and reproduction in any medium or format, as long as you give appropriate credit to the original author(s) and the source, provide a link to the Creative Commons licence, and indicate if changes were made. The images or other third party material in this article are included in the article's Creative Commons licence, unless indicated otherwise in a credit line to the material. If material is not included in the article's Creative Commons licence and your intended use is not permitted by statutory regulation or exceeds the permitted use, you will need to obtain permission directly from the copyright holder. To view a copy of this licence, visit http://creativecommons.org/licenses/by/4.0/ The Creative Commons Public Domain Dedication waiver (http://creativecommons.org/publicdomain/zero/1.0/) applies to the data made available in this article, unless otherwise stated in a credit line to the data. per capita between 1006 and 12,235 current US dollar), and low-income (with GNI per capita of less than 1006 current US dollar), countries with 59 and $1 \%$ registered vehicles have 80 and $13 \%$ of RTF, respectively [2].

Infrastructures such as land-usage planning, road layout, designing for road function and vehicle safety are important factors in preventing RTF but too much focus has been devoted on road users' characteristics and behaviors [3]. Most studies were conducted at micro levels on these factors, reporting the effect of road users' age, level of education, gender, drug and alcohol consumption, fatigue and other factors [3-5]. Research on social 
aspects of road collision at community level have shown that low socioeconomic status is associated with higher RTF as people living in deprived areas are more exposed to road traffic injuries and receive less efficient care $[6$, 7]. Confounding factors such as the use of older vehicles and vehicles with lower safety conditions might also exacerbate the situation. Vulnerable groups such as pedestrians, cyclists and motorcyclists which consist nearly half of the victims in road collisions are also more concentrated in deprived neighborhoods [8].

The perspective about road collision has changed in the last century from focusing only on individual behaviors to the importance of supportive environment. It was recognized that individual users do not have the ability to reduce the risk of collisions and governments have to play a more active role in reducing road collisions through legislative processes and various forms of regulation [9].

RTF should be approached as a social problem within the context of each individual community [10]. This would affect the priorities in interventions and legislations which may differ between and within countries.

Nowadays, there is more emphasis on the interaction between person, machine and environment in accident [11]. Haddon work recognizing the importance of the whole area of "mishaps" with all extra-rational conditions in accidents should be considered a turning point as he proposed a systematic approach rather than telescopic interventions in reducing RTF [12]. Based on Haddon's approach, the major source of errors can be identified, and appropriate interventions can be utilized to reduce the risk of accidents or to mitigate the adverse effects of accidents including crash severity, fatalities and injuries [13].

Along the same line, Al-Haji (2007) proposed road safety development index (RSDI) as a comprehensive conceptual framework to approach road collisions. In RSDI, three dimensions of performance, which include human, product and system performance are considered. He considered the system as a whole with the interactions between system, human and products. Accordingly, "system performance" would be the effectiveness of interventions in improving car safety, safer roads and safer use. Table 1 summarizes factors based on RSDI [10].

At the end of the Decade of Action, it is crucial to assess factors related to RTF. Most studies considered limited countries or factors, but scanty research has been carried out on the comparison between the less developed countries and high developed countries in this respect. Regarding these limitations, this study aimed to investigate the main factors associated with RTF at global level and accordingly, we adopted three different analytical methods to reach the best explanation.
Table 1 Road Safety Development Index (RSDI) Factors [10]

\begin{tabular}{ll}
\hline RSDI components & Factors \\
\hline Human performance & - Safer road user's "behavior" \\
Product performance & - Percentage change of death trend \\
& - Personal risk "death per population" \\
- Traffic risk "death per vehicle" \\
System performance & - Safer roads \\
& - Safer vehicles \\
& - Enforcement performance \\
& - Socioeconomic performance \\
\hline
\end{tabular}

\section{Methods}

\section{Data sources and indices}

We used the latest published data for safer roads and mobility, safer vehicles, and safer road users in the "Global status report on road safety 2015" and "Global status report on road safety 2018", published by WHO. The data of 180 countries were collected in 2013 and 2016 reports.

After list-wise deletion (eliminating samples with any missing values), 115 and 113 countries were selected from 2015 and 2018 reports, respectively. To consider different dimensions of the system performance, three aspects of safe system were chosen (safer roads and mobility, safer vehicles, and safer road users) based on WHO's reports for each country in the target years. The selected indices for each factor are available in Additional file 1: Table S1. Data on organizational performance (one of the RSDI components) was not available. "Death per population" was chosen for product performance. Data as "death per population" and "death per vehicles" factors were analyzed to obtain a more holistic view on the outcome.

Human Development Index (HDI) incorporated three major indices of life expectancy, GNI and GINI (named after Corrado Gini). Life expectancy refers to a long and healthy life, while education and GNI signify access to knowledge and decent standard of living, respectively. Regarding the GINI index, it is defined by the World Bank as the distribution of income (or, in some cases, consumption expenditure) among individuals or households within an economy [14]. Urban population and unemployment rate are other factors extracted from the United Nations Development Program and World Bank data center, with the former defined by the World Bank as "people living in urban areas as defined by national statistical offices" (per 100,000) [15] and the latter as "the share of the labor force that is without work but available for and seeking employment" [16]. These include the socioeconomic performance indices and factors in target years. We also considered the data from world happiness ("underpinnings of measuring and understanding subjective well-being") [17] and homicide rate (per 100,000 people) (World Bank definition: 
"Intentional homicides are estimates of unlawful homicides purposely inflicted") [18] as indices of the "behavior" of safer road user using the latest data available for each country. The RSDI components, factors and indices used, and the data sources are summarized in Table 2.

\section{Statistical analysis}

In road safety analysis, regression analysis such as linear regression models and Poisson regression has been the most conventional procedures to determine the factors affecting mortality rate. However, they have to meet certain assumptions and if we ignore the pre-defined assumptions, estimation would be inaccurate [21].

In order to overcome these limitations, other procedures such as classification and regression trees (CART) and multivariate adaptive regression splines (MARS) were applied in road safety analysis. They are considered decision tree procedures, and MARS can be viewed as the modified version of CART [22]. Acciani et al. (2011) showed that MARS and CART perform computationally well with small datasets [23]. In this research, two nonparametric statistical procedures, CART and MARS, were employed to determine and classify factors associated with mortality rate. Furthermore, the prediction indices were compared to a stepwise multivariate linear regression (SMLR).

\section{Classification and regression trees}

Classification and regression trees is a tree-based procedure, which can be applied for continuous and discrete variables. CART algorithm uses all data sets to build child nodes by splitting the subsets of the entire predictor variables. The goal is to obtain a maximum homogeneous subset of the data with regard to the dependent variable. Especially, when the target variable is continuous, CART uses the least squared deviation (LSD) criterion to build an optimal tree. The split is chosen to maximize the value of LSD criterion function. The split procedure performs recursively into terminal nodes [24].

\section{Multivariate adaptive regression splines model}

Multivariate adaptive regression splines is a nonparametric data mining procedure, which combines the classical linear regression, the spline functions and the recursive partitioning. It uses a set of piecewise function called basis function (BF) to determine relationships between a set of independent variables and the target variable [22, 25]. The general expression of MARS is defined as follow:

$$
\hat{y}=\beta_{0}+\sum_{m=1}^{M} \beta_{m} h_{m}(x)
$$

Where $\hat{y}$ is the target variable predicted by the model, $\mathrm{M}$ is the number of selected BFs, $\beta_{0}$ is the constant term, $\beta_{m}$ is the coefficient of the $m$-th BF and a $h_{m}(x)$ (hinge function) is one or more functions defined as follow:

$$
h(x)=\max (0, X-t)=\left\{\begin{array}{c}
X-t, \text { ift }<X \\
0, \text { otherwise }
\end{array}\right.
$$

$\mathrm{Or}$

$$
h(x)=\max (0, t-X)=\left\{\begin{array}{c}
t-X, \text { if } X<t \\
0, \text { otherwise }
\end{array}\right.
$$

The optimal model is chosen by generalized cross-

\begin{tabular}{|c|c|c|c|}
\hline $\begin{array}{l}\text { RSDI } \\
\text { components }\end{array}$ & Selected factors & Indices & Data sources \\
\hline \multirow[t]{2}{*}{$\begin{array}{l}\text { Human } \\
\text { performance }\end{array}$} & \multirow[t]{2}{*}{$\begin{array}{l}\text { Safer road user's } \\
\text { "behavior" }\end{array}$} & Happiness & $\begin{array}{l}\text { World happiness: Trends, explanations and distribution } \\
\text { (2013) and (2016) }[17,19]\end{array}$ \\
\hline & & Homicides (per 100,000 people) & World Bank [18] \\
\hline $\begin{array}{l}\text { Product } \\
\text { performance }\end{array}$ & $\begin{array}{l}\text { Personal risk "death per } \\
\text { population" }\end{array}$ & $\begin{array}{l}\text { Mortality caused by road traffic injury (per 100, } \\
000 \text { people) }\end{array}$ & $\begin{array}{l}\text { Global status report on road safety } 2015 \text { and } 2018 \text { [2, } \\
\text { 8] }\end{array}$ \\
\hline \multirow{7}{*}{$\begin{array}{l}\text { System } \\
\text { performance }\end{array}$} & Safer roads & & \multirow{3}{*}{$\begin{array}{l}\text { Global status report on road safety } 2015 \text { and } 2018 \text { [2, } \\
\text { 8] }\end{array}$} \\
\hline & Safer vehicles & & \\
\hline & $\begin{array}{l}\text { Enforcement } \\
\text { performance }\end{array}$ & & \\
\hline & \multirow{4}{*}{$\begin{array}{l}\text { Socioeconomic } \\
\text { performance }\end{array}$} & $\mathrm{HDI}$ & UNDP [20] \\
\hline & & Urban population (\% of total) & World Bank [15] \\
\hline & & GINI index (World Bank estimate) & World Bank [14] \\
\hline & & $\begin{array}{l}\text { Unemployment, total (\% of total labor force) } \\
\text { (modeled ILO estimate) }\end{array}$ & World Bank [16] \\
\hline
\end{tabular}
validation criterion (GCV) [26].

Table 2 RSDI components, Indices and data resources 


\section{Prediction performance indices}

In order to compare and assess the prediction performance of the models, the performance indices such as correlation coefficient $\left(r=\operatorname{cov}\left(y_{i}, \hat{y}_{i}\right) / \sigma_{y_{i}} \sigma_{\hat{y}_{i}}\right)$, root meansquared error $\left(R M S E=\sqrt{\sum_{i=1}^{n}\left(\hat{y}_{i}-y_{i}\right)^{2} / n}\right)$, mean absolute error $\left(M A E=\sum_{i=1}^{n}\left|\hat{y}_{i}-y_{i}\right| / n\right)$, relative absolute error $\left(R A E=\sum_{i=1}^{n}\left|\hat{y}_{i}-y_{i}\right| / \sum_{i=1}^{n}\left|y_{i}-\bar{y}\right|\right)$ and R-squared $\left(R^{2}=1-(\right.$ $\left.\left.\sum_{i=1}^{n}\left(\hat{y}_{i}-y_{i}\right)^{2} / \sum_{i=1}^{n}\left(y_{i}-\bar{y}\right)^{2}\right)\right)$ were estimated, where $y_{i}$ is the $i$ - th actual value of the dependent variable, $\hat{y}_{i}$ is the corresponding predicted value and $n$ is the number of observations [23].

\section{Results}

\section{The data set}

The data set includes HDI and its components (education, income and life expectancy), happiness, GINI index, urban population, unemployment, homicide, safer roads and mobility, safer vehicles and safer road users as independent variables. Using stated procedures, an initial analysis was performed found that the HDI was the most important variable amongst all independent variables (Additional file 1: Tables S2 to S8). Afterward, to identify the main factors related to RTF, HDI components have been considered in the analysis. Moreover, in order to assess the predictive capacity of the models, a 10-fold cross-validation was carried out. Table 3 presents common descriptive statistics for all the data set for 115 countries in 2013 and 113 countries in 2016. Furthermore, Tables 4 and 5 represent the frequency of countries based on human development analytical (United Nations Development Programme) and income analytical (World Bank classification schemes).

\section{Stepwise multivariate linear regression analysis}

Stepwise multivariate linear regression analysis was initiated with eleven independent variables. The entry and exit criteria (the $P$-value of $\mathrm{F}$-statistic) were set to 0.05 and 0.1 , respectively (SPSS software default F-statistic $P$ values, Finlay (2012) [27]). In 2013, the final model consisted of five variables that explained the mortality rate (detailed regression coefficients are available in Additional file 1: Table S9). Specifically, income, safer vehicles, GINI index, life expectancy and safer road users were selected, represented in the following equation:

$$
\begin{aligned}
\text { Mortality } & =45.38-13.61 * \text { income }-1.77 * \text { safe vehicle } \\
& +0.17 * \text { GINI }-17.91 * \text { life expectancy }-1.52 * \text { safe user }
\end{aligned}
$$

As can be seen in Eq. (1), all the coefficients carry the expected signs. The $R$-squared $\left(R^{2}\right)$ value is the proportion of the variation of target variable which can be explained by its explanatory variables. The $\mathrm{R}^{2}$ value for Eq. (1) is 0.746 , indicating a good model fit to the data (Table 6). Furthermore, Table 6 illustrates partial influence of the selected variables. Table 6 shows that $65 \%$ of

\begin{tabular}{|c|c|c|c|c|c|c|c|c|c|c|}
\hline \multirow[t]{2}{*}{ variable } & \multicolumn{2}{|c|}{ Minimum } & \multicolumn{2}{|c|}{ Maximum } & \multicolumn{2}{|l|}{ Range } & \multicolumn{2}{|l|}{ Mean } & \multicolumn{2}{|c|}{ Standard Deviation } \\
\hline & 2013 & 2016 & 2013 & 2016 & 2013 & 2016 & 2013 & 2016 & 2013 & 2016 \\
\hline$\overline{\text { Mortality rate }^{a}}$ & 2.8 & 2.7 & 36.2 & 35.9 & 33.4 & 33.2 & 16.561 & 16.122 & 9.219 & 9.2045 \\
\hline $\mathrm{HDI}$ & .340 & .351 & .946 & .951 & .606 & .600 & .7152 & .7252 & .156 & .157 \\
\hline GINI index & 25.4 & 25.0 & 63.4 & 63.0 & 38.0 & 38.0 & 37.457 & 37.078 & 7.902 & 7.4880 \\
\hline Homicides $^{b}$ & .183 & 2.905 & 74.28 & 7.526 & 74.096 & 82.559 & 6.489 & 5.351 & 9.944 & 1.1829 \\
\hline Happiness & 2.936 & .2835 & 7.693 & 82.842 & 4.757 & 4.621 & 5.460 & 6.217 & 1.105 & 10.684 \\
\hline Urban population ${ }^{c}$ & 15.437 & 12.388 & 97.776 & 97.919 & 82.339 & 85.531 & 58.908 & 59.635 & 20.949 & 21.485 \\
\hline Unemployment $^{d}$ & .3192 & .524 & 28.996 & 26.55 & 28.677 & 26.027 & 8.425 & 7.629 & 6.410 & 5.747 \\
\hline Safer roads and mobility & 0 & .50 & 5 & 5.00 & 5 & 4.5 & 3.16 & 3.668 & 1.405 & 1.131 \\
\hline Safer vehicles & 0 & 3.00 & 3 & 7.00 & 3 & 4 & 1.07 & 6.257 & 1.387 & .998 \\
\hline safer road users & 2 & 0.00 & 7 & 4.00 & 5 & 4 & 6.33 & 1.442 & .915 & 1.817 \\
\hline Education & .204 & .212 & .941 & .940 & .737 & .728 & .66396 & .67466 & .178088 & .181785 \\
\hline Income & .287 & .287 & .975 & .984 & .688 & .697 & 69570 & .70135 & .174642 & .176655 \\
\hline Life expectancy & .468 & .514 & .975 & .981 & .507 & .467 & .80230 & .81301 & .125288 & .117707 \\
\hline
\end{tabular}

Table 3 Common descriptive statistics of the variables

${ }^{a}$ road traffic injury per 100,000 people

${ }^{\mathrm{b}}$ Homicides per 100,000 people

${ }^{c} \%$ of total

$\mathrm{d}_{\%}$ of total labor force

HDI Human development index 
Table 4 Frequency of countries based on Human Development analytical category

\begin{tabular}{|c|c|c|c|c|c|c|c|c|c|c|}
\hline & \multicolumn{5}{|l|}{2013} & \multicolumn{5}{|l|}{2016} \\
\hline & Frequency & Percent & $\begin{array}{l}\text { Mean of } \\
\text { mortality } \\
\text { rate }\end{array}$ & $\begin{array}{l}\text { Minimum } \\
\text { mortality } \\
\text { rate }\end{array}$ & $\begin{array}{l}\text { Maximum } \\
\text { mortality } \\
\text { rate }\end{array}$ & Frequency & Percent & $\begin{array}{l}\text { Mean of } \\
\text { mortality } \\
\text { rate }\end{array}$ & $\begin{array}{l}\text { Minimum } \\
\text { mortality } \\
\text { rate }\end{array}$ & $\begin{array}{l}\text { Maximum } \\
\text { mortality } \\
\text { rate }\end{array}$ \\
\hline $\begin{array}{l}\text { Very } \\
\text { High }^{\mathrm{a}}\end{array}$ & 39 & 33.9 & 6.751 & 2.8 & 13.7 & 42 & 37.2 & 7.000 & 2.7 & 18.0 \\
\hline $\mathrm{High}^{\mathrm{b}}$ & 28 & 24.3 & 18.614 & 7.7 & 36.2 & 25 & 22.1 & 18.064 & 6.4 & 34.6 \\
\hline Medium $^{c}$ & 26 & 22.6 & 19.908 & 10.5 & 29.1 & 25 & 22.1 & 19.628 & 9.7 & 30.4 \\
\hline Low $^{d}$ & 22 & 19.1 & 27.382 & 14.2 & 35.0 & 21 & 18.6 & 27.881 & 21.4 & 35.9 \\
\hline Total & 115 & 100.0 & 16.561 & 2.8 & 36.2 & 113 & 100.0 & 16.122 & 2.7 & 35.9 \\
\hline
\end{tabular}

aery High: $\mathrm{HDI}>=0.8$

${ }^{\mathrm{b}} \mathrm{High}: 0.7<=\mathrm{HDI}<0.8$

cMedium: $0.55<=\mathrm{HDI}<0.7$

Low: $\mathrm{HDI}<0.55$

HDI Human development index

the variation of the dependent variable is explained by income.

In 2016, the final model consists of three variables that explain mortality rate (detailed regression coefficients are shown in Additional file 1: Table S10). Specifically, income, GINI index and life expectancy were selected, represented in the following equation:

$$
\begin{aligned}
\text { Mortality }= & 37.47-26.91 * \text { income } \\
& +0.35 * \text { GINI }-19.16 * \text { life expectancy }
\end{aligned}
$$

As can be seen in Eq. (2), all the coefficients carry the expected signs. The $\mathrm{R}^{2}$ value for Eq. (2) is 0.784 , representing a good model fit to the data (Table 7). As can be seen in Table 7, 67\% of the variation of the dependent variable is explained by income.

\section{Classification and regression trees}

Classification and regression trees analysis was performed using the eleven independent variables. Furthermore, in order to obtain an optimal model, a 10-fold cross-validation was carried out. In 2013, the result of CART is a tree with 7 non-terminal nodes and 8 terminal nodes (Fig. 1). From the 11 independent variables, CART used income, life expectancy, urban population, unemployment and homicide to build the optimal model.

In 2016, the result of CART is a tree with 6 nonterminal nodes and 7 terminal nodes (Fig. 2). CART used education, income, life expectancy, unemployment and happiness to build the optimal model. The rules and the mean of mortality rate from the final tree are available in Additional file 1: Tables S11 and S12. Moreover, the categorization of countries based on terminal nodes are shown in Additional files 2 and 3.

\begin{tabular}{|c|c|c|c|c|c|c|c|c|c|c|}
\hline & \multicolumn{5}{|l|}{2013} & \multicolumn{5}{|l|}{2016} \\
\hline & Frequency & Percent & $\begin{array}{l}\text { Mean of } \\
\text { mortality } \\
\text { rate }\end{array}$ & $\begin{array}{l}\text { Minimum } \\
\text { mortality } \\
\text { rate }\end{array}$ & $\begin{array}{l}\text { Maximum } \\
\text { mortality } \\
\text { rate }\end{array}$ & Frequency & Percent & $\begin{array}{l}\text { Mean of } \\
\text { mortality } \\
\text { rate }\end{array}$ & $\begin{array}{l}\text { Minimum } \\
\text { mortality } \\
\text { rate }\end{array}$ & $\begin{array}{l}\text { Maximum } \\
\text { mortality } \\
\text { rate }\end{array}$ \\
\hline $\begin{array}{l}\text { Very } \\
\text { High }^{a}\end{array}$ & 38 & 33.0 & 7.079 & 2.8 & 23.4 & 34 & 30.1 & 6.003 & 2.7 & 13.4 \\
\hline $\begin{array}{l}\text { Upper- } \\
\text { Middle }^{b}\end{array}$ & 31 & 27.0 & 18.387 & 7.7 & 36.2 & 30 & 26.5 & 17.220 & 6.4 & 34.6 \\
\hline $\begin{array}{l}\text { Lower- } \\
\text { Middlec }\end{array}$ & 30 & 26.1 & 20.813 & 10.5 & 29.1 & 34 & 30.1 & 19.874 & 9.7 & 30.1 \\
\hline Low $^{d}$ & 16 & 13.9 & 27.569 & 13.6 & 35.0 & 15 & 13.3 & 28.360 & 15.9 & 35.9 \\
\hline Total & 115 & 100.0 & 16.561 & 2.8 & 36.2 & 113 & 100.0 & 16.122 & 2.7 & 35.9 \\
\hline
\end{tabular}

Table 5 Frequency of countries based on income analytical category

${ }^{a}$ Very High: GNI > $=\$ 12,736$

bupper- Middle: $\$ 4125<=\mathrm{GNI}<\$ 12,736$

'Lower- Middle: $\$ 1045<=\mathrm{GNI}<\$ 4125$

dLow: GNI < \$1045

GNI Gross National Income 
Table 6 Stepwise Multivariate Linear Regression: model summary (2013)

\begin{tabular}{lllll}
\hline Model & R & R square & Adjusted R square & R square change \\
\hline 1 & $.804^{\mathrm{a}}$ & .646 & .643 & .646 \\
2 & $.832^{\mathrm{b}}$ & .693 & .688 & .047 \\
3 & $.849^{\mathrm{c}}$ & .720 & .713 & .027 \\
4 & $.857^{\mathrm{d}}$ & .734 & .724 & .013 \\
5 & $.864^{\mathrm{e}}$ & .746 & .734 & .012 \\
\hline
\end{tabular}

a Predictors: Constant, income 2013

b Predictors: Constant, income 2013, safer vehicles 2013

c Predictors: Constant, income 2013, safer vehicles 2013, GINI index 2013

d Predictors: Constant, income 2013, safer vehicles 2013, GINI index 2013, life expectancy 2013

e Predictors: Constant, income 2013, safer vehicles 2013, GINI index 2013, life expectancy 2013, safeuser2013

\section{Multivariate adaptive regression splines model}

A first-order MARS was carried out, so the basis functions of the models consist of linear splines. In order to create smaller models during the pruning step, the GCV criterion was replaced with 10 -fold cross-validation. In Table 8 , the basis functions and their coefficients are shown in detail for 2013 data set. Then, the MARS prediction function is represented in the following equation:

$$
\begin{aligned}
Y= & 16.99-1.2 * B F 1+0.09 * B F 2 \\
& +191.51 * B F 3-437.70 * B F 4+225.58 * B F 5 \\
& +47.72 * B F 6 \\
& +36.05 * B F 7-66.44 * B F 8-36.37 * B F 9
\end{aligned}
$$

To illustrate the interpretation of MARS outcomes, consider the BF2 given in Table 8

$$
\begin{aligned}
\mathrm{BF} 2 & =\max (0, \text { urban population }-38.979) \\
& =\left\{\begin{array}{c}
\text { GINI index }-38.979, \text { if } 38.979<\text { urban population } \\
0, \text { otherwise }
\end{array}\right.
\end{aligned}
$$

Therefore, if the GINI index of a country is 40.979, then the MARS model predicts the mortality rate increase by 0.18 (i.e., $\left.0.09^{*}(40.979-38.979)\right)$; otherwise, if the GINI index of a country is less than 38.979, then GINI index has no effect on mortality rate.

As shown in Table 8, the MARS model contains 9 basis functions. It can be observed that five variables play an important role in determining mortality rate.

Table 7 Stepwise Multivariate Linear Regression: model summary (2016)

\begin{tabular}{lllll}
\hline Model & R & R square & Adjusted R square & R square change \\
\hline 1 & $.821^{\mathrm{a}}$ & .674 & .671 & .674 \\
2 & $.877^{\mathrm{b}}$ & .769 & .765 & .095 \\
3 & $.885^{\mathrm{c}}$ & .784 & .778 & .015 \\
\hline
\end{tabular}

a Predictors: Constant, income 2016

b Predictors: Constant, income 2016, GINI index 2016

c Predictors: Constant, income 2016, GINI index 2016, life expectancy 2016
These variables include safer vehicles, urban population, education, income, and life expectancy. The detailed impact of each basis function on mortality rate for 2013 data set are available in Additional file 1: Table S13. Based on Table S13 results, the mean of mortality rate of countries decreases when (safer vehicles $>0$ ), (urban population $>38.979$ ) and (life expectancy $>0.613$ ). Furthermore, it can be inferred that the mean of mortality rate of countries decreased with increase of education and income.

Table 9 shows the basis functions and their coefficients for 2016 data set. The MARS prediction function is represented in the follow equation:

$$
\begin{aligned}
Y= & 20.9-0.29 * B F 1+3.68 * B F 2-30.82 * B F 3 \\
& +29.53 * B F 4-52.24 * B F 5 .
\end{aligned}
$$

As can be seen in Table 9, the MARS model contains 5 basis functions. It can be observed that five variables play an important role in determining mortality rate. These variables are GINI index, happiness, education, income, and life expectancy. For more details on the impact of each basis function on mortality rate for 2016 data set refer to Additional file 1: Table S14. According to Table S14, when (happiness < 5.121) and (income < $0.549)$ we have an increase in mean of mortality rate of countries, while the mean of mortality rate of countries increases when $(\mathrm{GINI}<45$ ), (income $<0.549$ ) and (life expectancy $>0.865)$.

\section{Changes in road traffic fatality}

Comparing RTF data of 2013 and 2016 indicates that more than $20 \%$ of the change occurred in 18 countries, and more than $30 \%$ in 8 countries. Table 10 shows countries with more than $30 \%$ of change in RTF with corresponding growth rate in GINI index and HDI between these years.

\section{Prediction performance of the models}

The indices described in the previous section are shown in Table 11 for each model. The values of indices indicated a good fit to the data for each model. It can be observed that CART has the best performance among other methods.

Variable importance measure (VIM) is one of the useful outputs from the CART and MARS models, which reflects the effect of predictor variables on the model. Table 12 indicates the relative variable importance computed for the 9 independent variables in 2013 and 2016. There were considerable differences between the models regarding the importance of independent variables, which will be discussed in the next section. 


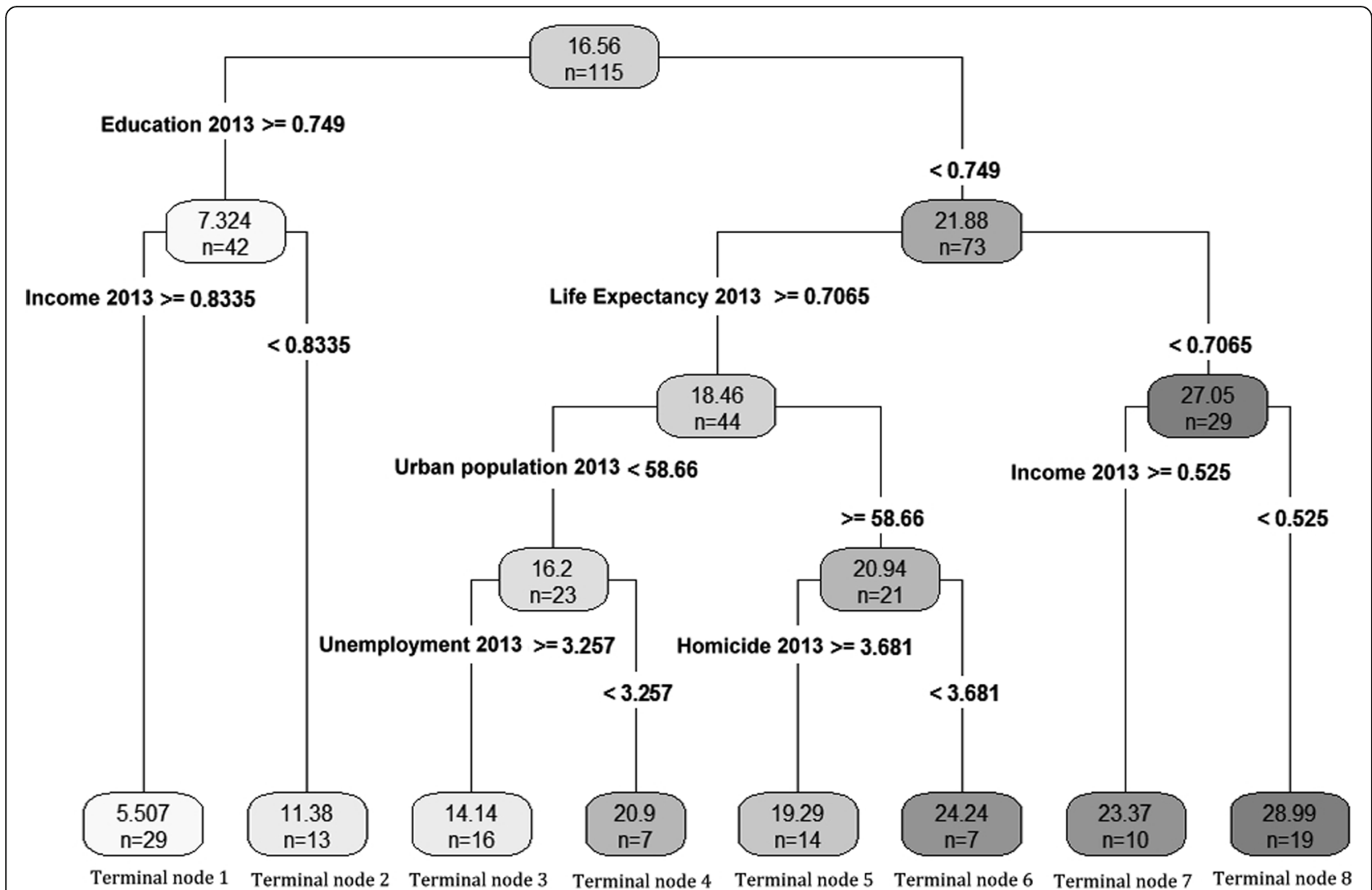

Fig. 1 Optimal tree created by CART (2013). The number of countries and their associated mean of mortality rate are shown at each terminal node

\section{Discussion}

This study aims to investigate the main factors related to road traffic fatality (RTF) around the world. Based on RSDI framework, we considered human performance, product performance and system performance. In this context, two main factors which play a critical role in RTF in both 2013 and 2016 years were HDI and GINI indices. Amongst the selected factors, the results showed that HDI was the main determinant, which was related to RTF. The results indicate that from 2013 to 2016, the mortality rate decreased along with GINI index, while HDI increased in this period (Additional file 1: Tables S4 to S6). In both years, HDI can explain more than $66 \%$ of RTF variations (Additional file 1: Tables S2 and S3).

To the best of our knowledge, there is scanty research similar in scope to the present study, and none as broad in data collection as our study. Most studies use panel data to determine factors which influence RTF. However, in these studies the number of indices or the number of countries is limited. Al-Haji found a strong relationship between HDI and RSDI and mentioned that by boosting the income of countries, more safer vehicles will be used and their investment on road infrastructure will be promoted [10, 28]. Yannis (2014) investigated 27
European countries between 1975 to 2011 and find out that by increasing Gross Domestic Product (GDP) (one of HDI components), RTF also increase in these countries [29]. Another investigation in 27 upper-middleincome countries in the three continents reveals that increasing GDP has a significant impact on RTF [30]. Bester (2001) found that passenger car ownership, HDI and the percentage of other vehicles had an impact on road traffic death and HDI was able to explain 53\% of the variation of road death [31]. While in our study we found that HDI in SMLR was able to explain nearly $66 \%$ of the variation of mortality rate in 2013 and $72 \%$ in 2016. Melinder (2007) investigated 15 European countries and found a relationship amongst fatal death in road collisions, wealth and religion. She concluded that economic level has an impact on RTF to some point and other factors subsequently play a role [32]. A much broader study on 176 countries accounted for seven factors influencing road traffic injuries. These factors include income level of a country and some other factors that could be categorized under the subheading of the "safer road users" [33].

A total of 101 countries have valid data for both 2013 and 2016 (Additional file 4). Among these, the RTF of 


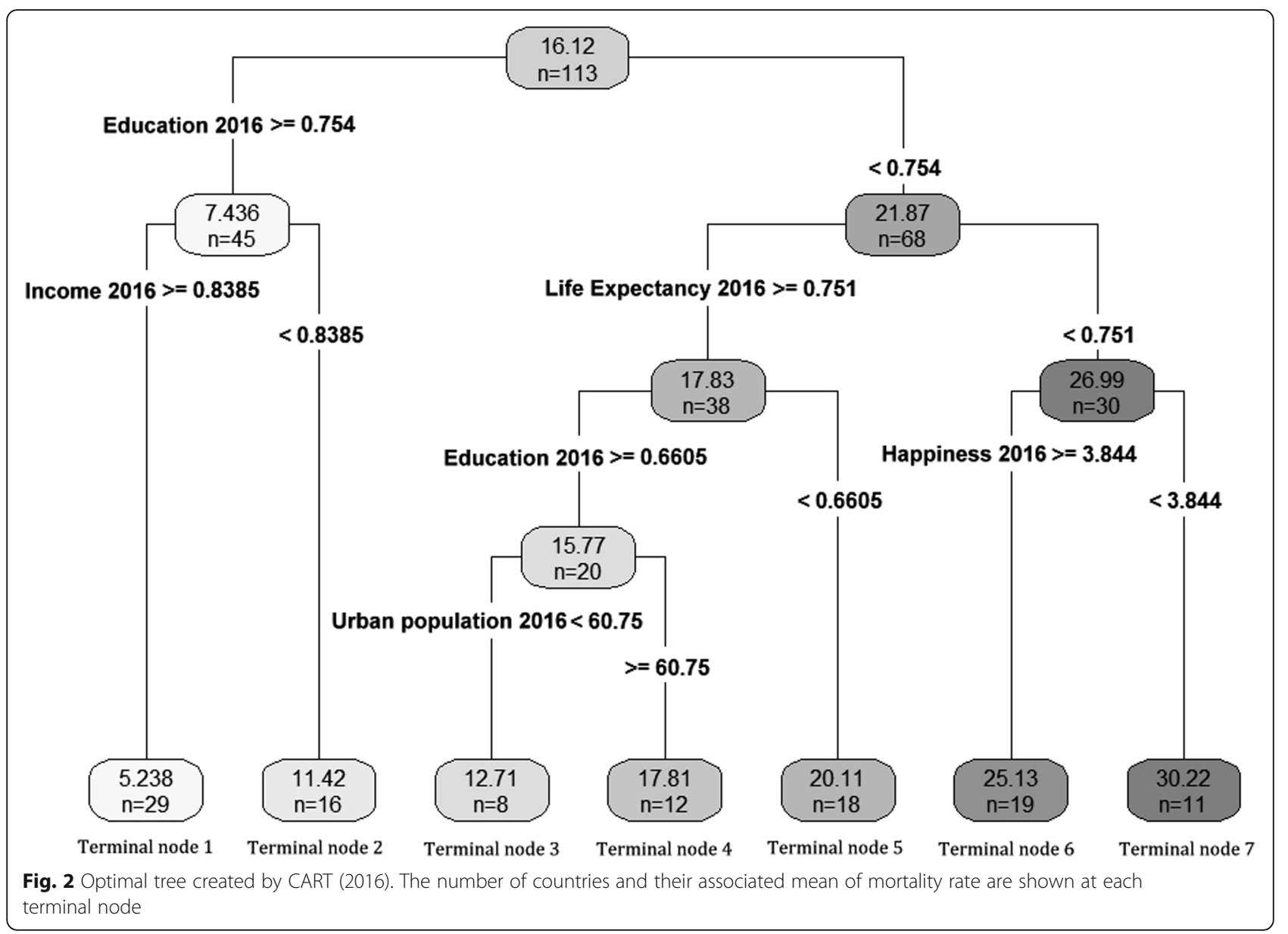

18 countries changed more than $\pm 20 \%$ (Additional file 5 ) and in 8 countries more than $\pm 30 \%$ (Additional file 6 ). In this regard, by considering different variables related to RTF, only GINI index seemed to have a relationship with RTF in these 8 countries. RTF decreased

Table 8 Basis functions of the MARS and their coefficients (2013)

\begin{tabular}{lll}
\hline Variables & Basis Function & coefficients \\
\hline (Intercept) & & 16.99 \\
BF1 & safer vehicles 2013 & -1.2 \\
BF2 & $h$ (urban population 2013-38.979) & 0.09 \\
BF3 & $h$ (education 2013-0.583) & 191.51209 \\
BF4 & $h$ (education 2013-0.623) & -437.70114 \\
BF5 & $h$ (education 2013-0.654) & 225.58727 \\
BF6 & $h$ (income 2013-0.59) & 47.72427 \\
BF7 & $h$ (0.745 - income 2013) & 36.05110 \\
BF8 & $h$ (income 2013-0.745) & -66.43674 \\
BF9 & $h$ (Life Expectancy 2013-0.613) & -36.36855 \\
\hline
\end{tabular}

$B F$ Basis function, h Hinge function dramatically in 5 countries in these three years more than $30 \%$, namely Iran, Belarus, Bolivia, Macedonia and Kyrgyzstan. Except Iran, other four countries in these years experienced a reduction in their GINI index. On the other hand, RTF in three countries increased more than 30\%, namely India, Turkey and Iceland. Except India, other two countries in these years are faced with an increasing rate in GINI index. Thus, the behavior analysis of Iran and India revealed different results from the other six countries. In the case of Iran (however not

Table 9 Basis functions of the MARS and their coefficients (2016)

\begin{tabular}{lll}
\hline Variables & Basis Function & coefficients \\
\hline (Intercept) & & 20.9 \\
BF1 & $h(45-$ GINI index 2016) & -0.29 \\
BF2 & $h(5.121$ - happiness 2016) & 3.68 \\
BF3 & $h($ education 2016-0.631) & -30.82 \\
BF4 & $h(0.549-$ income 2016) & 29.53 \\
BF5 & $h($ life expectancy 2016-0.865) & -52.24 \\
\hline BF Basis function, h Hinge function
\end{tabular}

$B F$ Basis function, h Hinge function 
Table 10 Countries with more than 30\% change in RTF with correspondent growth rate in GINI index and HDI

\begin{tabular}{llllllllll}
\hline Country & $\begin{array}{l}\text { RTF rate } \\
\mathbf{2 0 1 3}\end{array}$ & $\begin{array}{l}\text { RTF rate } \\
\mathbf{2 0 1 6}\end{array}$ & $\begin{array}{l}\text { RTF growth } \\
\text { rate }\end{array}$ & $\begin{array}{l}\text { GINI index } \\
\mathbf{2 0 1 3}\end{array}$ & $\begin{array}{l}\text { GINI index } \\
\mathbf{2 0 1 6}\end{array}$ & $\begin{array}{l}\text { GINI index growth } \\
\text { rate }\end{array}$ & $\begin{array}{l}\text { HDI } \\
\mathbf{2 0 1 3}\end{array}$ & $\begin{array}{l}\text { HDI } \\
\mathbf{2 0 1 6}\end{array}$ & $\begin{array}{l}\text { HDI growth } \\
\text { Rate }\end{array}$ \\
\hline Iran & 32.1 & 20.5 & -36.14 & 37.4 & 40.0 & 6.95 & 0.784 & 0.796 & 1.53 \\
Belarus & 13.7 & 8.9 & -35.04 & 26.6 & 25.3 & -4.89 & 0.804 & 0.805 & 0.12 \\
Bolivia & 23.2 & 15.5 & -33.19 & 47.6 & 44.6 & -6.30 & 0.668 & 0.689 & 3.14 \\
Macedonia & 9.4 & 6.4 & -31.91 & 36.2 & 35.6 & -1.66 & 0.743 & 0.756 & 1.75 \\
Kyrgyzstan & 22.0 & 15.4 & -30.00 & 28.8 & 26.8 & -6.94 & 0.658 & 0.669 & 1.67 \\
India & 16.6 & 22.6 & 36.14 & 35.7 & 35.7 & 0.00 & 0.607 & 0.636 & 4.78 \\
Turkey & 8.9 & 12.3 & 38.20 & 40.2 & 41.9 & 4.23 & 0.771 & 0.787 & 2.07 \\
Iceland & 4.6 & 6.6 & 43.48 & 25.4 & 27.8 & 9.45 & 0.920 & 0.933 & 1.41
\end{tabular}

RTF Road traffic fatalities, HDI Human development index

limited to Iran), this could be explained by inconsistency between the reported data of the country and WHO estimation. However, it should be mentioned that from 2006 to 2012 Iran faced a decrease in the absolute number of deaths (approximately 27\%) [34]. On the other hand, the most recent available data for GINI index for India is attributed to the year 2011. Hence, as the most recent data have been used in this study (mentioned in methodology section), for GINI index in 2013 and 2016, there was no difference between these two years. These results show the importance of GINI index mainly for countries with more than 30\% changes. However, there is a need to investigate the relation between RTF and GINI index in a long run.

All the eight countries subject to analysis, except Iceland (very high HDI rank), had the HDI between 0.6 and 0.8 (high and medium HDI rank), which experienced the most radical changes. It is postulated that these countries might be more fragile to GINI index changes.

In this study, three different procedures for analyzing data in 115 countries were applied in 2013 and for 2016, 113 countries were assessed. As HDI is the main factor related to RTF, three components of HDI (income, education and life expectancy) were considered alongside other factors. By using SMLR, income is the main factor related to RTF in both years and it could explain 64 and $67 \%$ of RTF variation in 2013 and 2016, respectively. It is noticeable that when income is the main factor to explain RTF, GINI index also affects our output in both years. In 2013, safer vehicles, life expectancy and safer road users were also related to RTF. However, these factors were not present in 2016.

Other two procedures have better explanation than SMLR. CART and MARS models reveal that education is the main factor related to RTF among other factors. Variable importance table shows that for both years education, income and life expectancy (HDI components) are the main factors related to RTF respectively. For 2013, the cut-off point of education index is 0.749 and countries which have higher education index have lower RTF. In this context, countries with income index of more than 0.8335 have the lowest RTF rate (29 countries). On the other hand, for countries with education index of lower than 0.749 , life expectancy has a significant relationship with RTF. Life expectancy cut-off point for these countries is 0.7065 and countries with higher life expectancy have lower rate of RTF (Additional file 2). These results have been approximately confirmed by MARS model, where education index, income index and life expectancy index have the highest coefficient than other factors. This trend can also be seen in 2016. In this year, for CART model, education index cut-off point is 0.754 and countries with income index of higher than 0.8385 have the lowest RTF (29 countries). On the other hand, countries with education index of lower than 0.754 , life expectancy with the cut-off point of more than 0.751 have lower RTF than other countries in this category. In MARS model, these three variables also have the highest impact on RTF (Additional file 3).

In addition, based on CART and MARS models, legislative factors do not have valid relationships with RTF

Table 11 Prediction performance measures of the models

\begin{tabular}{|c|c|c|c|c|c|c|c|c|c|c|}
\hline \multirow[t]{2}{*}{ Model } & \multicolumn{2}{|l|}{$r$} & \multicolumn{2}{|l|}{ RMSE } & \multicolumn{2}{|l|}{ MAE } & \multicolumn{2}{|l|}{ RAE } & \multicolumn{2}{|l|}{$R^{2}$} \\
\hline & 2013 & 2016 & 2013 & 2016 & 2013 & 2016 & 2013 & 2016 & 2013 & 2016 \\
\hline SMLR & 0.86 & 0.88 & 4.62 & 4.27 & 3.21 & 3.11 & 0.40 & 0.39 & 0.75 & 0.78 \\
\hline CART & 0.91 & 0.91 & 3.80 & 3.71 & 2.75 & 2.71 & 0.34 & 0.34 & 0.82 & 0.84 \\
\hline MARS & 0.90 & 0.90 & 4.02 & 3.90 & 2.93 & 2.80 & 0.36 & 0.35 & 0.81 & 0.82 \\
\hline
\end{tabular}

$r$ correlation coefficient, RMSE Root mean squared error, MAE Mean absolute error, RAE Relative absolute error, SMLR Stepwise multivariate linear regression, CART Classification and regression trees, MARS Multivariate adaptive regression splines 
Table 12 Importance of variables included in the CART and MARS model

\begin{tabular}{llllll}
\hline Variable & \multicolumn{3}{l}{ Importance in CART } & & Importance in MARS \\
\cline { 2 - 3 } \cline { 6 - 6 } & $\mathbf{2 0 1 3}$ & $\mathbf{2 0 1 6}$ & & $\mathbf{2 0 1 3}$ & $\mathbf{2 0 1 6}$ \\
\hline Education & 21 & 21 & 100 & 100 \\
Income & 19 & 18 & 19.6 & 10.6 \\
Life expectancy & 17 & 17 & 38.7 & 15 \\
Safer vehicles & 14 & 13 & 5 & unused \\
Happiness & 12 & 5 & & unused & 38.5 \\
Homicide & 10 & 12 & unused & unused \\
Urban population & 3 & 2 & & 16.5 & unused \\
Unemployment & 2 & 1 & & unused & unused \\
GINI index & 1 & unused & & unused & 19.5 \\
Safer road users & unused & 11 & & unused & unused \\
Safer roads and mobility & unused & unused & unused & unused \\
\hline
\end{tabular}

CART Classification and regression trees, MARS Multivariate adaptive regression splines

for both years. However, regarding CART model and factor importance table, safer vehicles could be related to RTF if HDI components are not considered.

By considering World Bank classification 2016 [35] in the CART model for both 2013 and 2016, countries with the least RTF fatality (29 countries for both years), are high-income countries (GNI of more than \$12,736) with very high HDI rank (HDI of more than 0.8). On the other hand, countries with the highest rate of RTF (19 countries for 2013 and 11 countries for 2016) are mostly low-income (GNI of \$1045 or less) and low developed (HDI less 0.55). Therefore, based on the above discussion, we can conclude that for both groups, the level of education is the most important factor related to RTF and at the next level, income plays a central role for both high- and low-income countries. For other countries, although it can be seen that this trend is mainly valid (higher rate of HDI and education associated with less RTF), it can be concluded that by enhancing education rate and the income might reduce the RTF rate.

In 2013, among 38 high-income countries, only four countries (Republic of Korea, Chile, Uruguay and Brazil) had an RTF of more than one-third of the global RTF range (maximum (RTF) - minimum (RTF)). However, in 2016, only Chile and Uruguay have had an RTF of more than 12 per 100,000 population among the high-income countries. Republic of Korea reduced its RTF from 12 to 9.8 per 100,000 population between 2013 and 2016, and in 2016 Brazil was not ranked as a high-income country and was downgraded to a middle-high income country. On the other hand, except Bangladesh and Nepal (with RTF 13.6 and 17 per 100,000 population, respectively) other low-income countries had an RTF of more than 25 per 100,000 population. In 2016, Bangladesh was promoted to a middle-income country and Nepal had an RTF of lower than 16 per 100,000 population. Other low-income countries had an RTF of more than 23 per 100,000 population. Regarding this data, there is a need to consider these exceptions and investigate the cause of a different behavior in the mentioned countries than other countries in their category. For example, Nepal can be a good case study among low-income countries, which reduced its RTF with limited resources.

\section{Limitations}

This is a cross-sectional study and there is a need for a longitudinal study to assess the impact of different factors on mortality rate and investigate the casual relations among HDI components with RTF rate. Although we tried to consider nearly 180 countries, missing data reduced our cases to approximately 115 countries. Besides, however we have considered happiness and homicide rate for behavioral dimension of RSDI, we did not consider some individual-level variables, such as personality or personal ability. Finally, some important factors such as road network size of countries or their investment in road industry were not accessible for most countries in 2013 and 2016; hence, we did not consider these factors.

\section{Conclusion}

To sum up, although legislative factors, urban population and happiness can play important roles in the prediction of RTF for some countries, we found that HDI can be the core predictor for 2013 and 2016 in most countries. Considering HDI components gives us a wider view about factors related to RTF. By comparing SMLR, CART, and MARS models, it can be seen that CART provides a better explanation than others with $R^{2}$ of nearly $83 \%$ for both years. Based on CART results, education can play a central role in decreasing RTF in countries and by investing on public education via school, countries could reduce their road fatality. For countries with a high rate of education index, income plays an important role too. This can be due to their investigation on road safety and using better vehicles. For countries with lower education, better medical care can reduce their vulnerability to RTF. In addition, high-income countries mostly have the lowest number of RTF and low-income countries have the highest rate of RTF. As a result, policymakers should consider RTF as a socioeconomic problem which requires both social and economic solutions.

\section{Supplementary information}

Supplementary information accompanies this paper at https://doi.org/10 1186/s12889-020-09491-x.

Additional file 1. Details of methodology. 
Additional file 2. Categorization of countries based on CART result in 2013.

Additional file 3. Categorization of countries based on CART result in 2016.

Additional file 4. Countries which have valid data for both 2013 and 2016.

Additional file 5. Countries changed more than $\pm 20 \%$ in RTF.

Additional file 6. Countries changed more than $\pm 30 \%$ in RTF.

\section{Abbreviations}

RTF: Road traffic fatalities; RSDI: Road Safety Development Index; CART: Classification and Regression Trees; MARS: Multivariate Adaptive Regression Splines; HDI: Human Development Index; WHO: World Health Organization; SMLR: Stepwise Multivariate Linear Regression; LSD: Least Squared Deviation; BF: basis function; GCV: Generalized Cross-Validation criterion; RMSE: Root Mean-Squared Error; MAE: Mean Absolute Error; RAE: Relative Absolute Error; GDP: Gross Domestic Product

\section{Acknowledgements}

Not applicable.

\section{Authors' contributions}

Conceptualization: KBL, MRRH and SG; Data curation: MRRH and MS; Statistical analysis: MS and MRRH; Investigation: $K B L, M R R H, S G$ and MS; Methodology: MRRH, MS and SG; Supervision: KBL and SG; Validation: SG, KBL and MRRH; Visualization: MRRH and SG; Writing - original draft: MRRH and MS; Writing - review \& editing: MRRH and MS. All authors read and approved the final manuscript.

\section{Funding}

None.

\section{Availability of data and materials}

The datasets used and/or analyzed during the study are available from the corresponding author on reasonable request.

\section{Ethics approval and consent to participate}

All procedures performed in this study were in accordance with the ethical standards of the institutional research committee and with the 1964 Helsinki declaration and its later amendments or comparable ethical standards. Approval was obtained from the Ethics Committee of Shiraz University of Medical Sciences. Consent to participate was not applicable to this study. Ethics committee approval: IR.SUMS.REC.1397.487.

\section{Consent for publication}

Not applicable.

\section{Competing interests}

The authors declare that they have no competing interests.

Received: 16 January 2020 Accepted: 1 September 2020

Published online: 17 September 2020

\section{References}

1. World Health Organization. Global health estimates 2016 summary tables: global deaths by cause, age and sex, 2000-2016. Geneva, Switzerland: World Health Organization; 2018.

2. World Health Organization. Global status report on road safety 2018: summary. Geneva: World Health Organization; 2018.

3. Mohan D, Khayesi M, Tiwari G, Nafukho FM. Road traffic injury prevention training manual. Geneva: World Health Organization; 2006.

4. Begg DJ, Langley JD, Williams SM. A longitudinal study of lifestyle factors as predictors of injuries and crashes among young adults. Accid Anal Prev. 1999:31(1-2):1-1.

5. Hasselberg M, Vaez M, Laflamme L. Socioeconomic aspects of the circumstances and consequences of car crashes among young adults. Soc Sci Med. 2005;60(2):287-95.
6. Hosking J, Ameratunga S, Exeter D, Stewart J, Bell A. Ethnic, socioeconomic and geographical inequalities in road traffic injury rates in the Auckland region. Aust N Z J Public Health. 2013;37(2):162-7.

7. Klaitman SS, Solomonov E, Yaloz A, Biswas S. The incidence of road traffic crashes among young people aged 15-20 years: differences in behavior, lifestyle and sociodemographic indices in the Galilee and the Golan. Front Public Health. 2018;6:202.

8. World Health Organization. Global status report on road safety 2015 Geneva: World Health Organization; 2015.

9. Leveson N. A new accident model for engineering safer systems. Saf Sci. 2004:42(4):237-70.

10. Al-Haji G. Road safety development index: Theory, philosophy and practice (Doctoral dissertation, Linköping University Electronic Press).; 2007.

11. Goetsch D. Occupational safety and health for technologies, engineers and managers, 7th edition, vol. Chapter 3. New Jersey: Pearson Prentice Hill; 2011. p. 32-50.

12. Haddon $\mathrm{W} \mathrm{Jr}$. The changing approach to the epidemiology, prevention, and amelioration of trauma: the transition to approaches etiologically rather than descriptively based. American journal of public health and the Nations health. 1968;58(8):1431-8.

13. Peden M, Scurfield R, Sleet D, Mohan D, Hyder AA, Jarawan E, et al. World report on road traffic injury prevention. Geneva: World Health Organization; 2004.

14. World Bank. GINI index (World Bank estimate); 2019. https://data.worldbank. org/indicator/SI.POV.GINI.

15. World Bank. Urban population (\% of total); 2019. https://data.worldbank.org/ indicator/SP.URB.TOTL.in.zs.

16. World Bank. Unemployment, total (\% of total labor force) (modeled ILO estimate); 2019. https://data.worldbank.org/indicator/SL.UEM.TOTL.ZS.

17. Helliwell JF, Layard PR, Sachs J, editors. World happiness report 2016 update: volume I. Sustainable Development Solutions Network; 2016.

18. World Bank. Homicides (per 100,000 people); 2019. https://data.worldbank org/indicatorNC.IHR.PSRC.P5.

19. Helliwell JF, Wang S. World happiness: trends, explanations and distribution. World happiness report. 2013;201(3):8-37.

20. United Nations Development Programme. Human Development Data (1990-2018); 2019. http://hdr.undp.org/en/data.

21. Chang LY, Chen WC. Data mining of tree-based models to analyze freeway accident frequency. J Saf Res. 2005;36(4):365-75.

22. Hastie T, Tibshirani R, Friedman J. The elements of statistical learning: data mining, inference, and prediction, second edition. 2nd ed, vol. Chapter 9. New York: Springer; 2016. p. 305-29.

23. Acciani C, Fucilli V, Sardaro R. Data mining in real estate appraisal: a model tree and multivariate adaptive regression spline approach. Aestimum. 2011; 23:27-45.

24. Breiman L, Friedman J, Stone CJ, Olshen RA. Classification and regression trees, vol. Chapter 8: CRC press; 1984. p. 216-64

25. Friedman JH. Multivariate adaptive regression splines. Ann Stat. 1991;1:1-67.

26. Craven P, Wahba G. Smoothing noisy data with spline functions. Numer Math. 1978;31(4):377-403.

27. Finlay S. Credit scoring, response modeling, and insurance rating: a practical guide to forecasting consumer behavior. London: Palgrave Macmillan; 2012 Jun 26. Chapter 7: p. 170-173.

28. Al-Haji G. Towards a road safety development index (RSDI): development of an international index to measure road safety performance (doctoral dissertation, Linköping University electronic press); 2005.

29. Yannis G, Papadimitriou E, Folla K. Effect of GDP changes on road traffic fatalities. Saf Sci. 2014;63:42-9.

30. Ali Q, Yaseen MR, Khan MT. The causality of road traffic fatalities with its determinants in upper middle income countries: a continent-wide comparison. Transp Res A Policy Pract. 2019;119:301-12.

31. Bester CJ. Explaining national road fatalities. Accid Anal Prev. 2001;33(5):663-72.

32. Melinder K. Socio-cultural characteristics of high versus low risk societies regarding road traffic safety. Saf Sci. 2007:45(3):397-414.

33. Jafari SA, Jahandideh $\mathrm{S}$, Jahandideh $\mathrm{M}$, Asadabadi EB. Prediction of road traffic death rate using neural networks optimised by genetic algorithm. Int J Inj Control Saf Promot. 2015;22(2):153-7.

34. Lankarani KB, Sarikhani Y, Heydari ST, Joulaie H, Maharlouei N, Peimani P, Ahmadi SM, Khorasani-Zavareh D, Soori H, Davoudi-Kiakalayeh A, Masoumi G. Traffic accidents in Iran, a decade of progress but still challenges ahead. Med J Islam Repub Iran. 2014;28:96. 
35. Fantom N, Serajuddin U. The World Bank's classification of countries by income (English). Policy Research working paper; no. WPS 7528.

Washington, D.C: World Bank Group; 2016. http://documents.worldbank.org/ curated/en/408581467988942234/The-World-Banks-classification-of-

countries-by-income.

\section{Publisher's Note}

Springer Nature remains neutral with regard to jurisdictional claims in published maps and institutional affiliations.

Ready to submit your research? Choose BMC and benefit from:

- fast, convenient online submission

- thorough peer review by experienced researchers in your field

- rapid publication on acceptance

- support for research data, including large and complex data types

- gold Open Access which fosters wider collaboration and increased citations

- maximum visibility for your research: over $100 \mathrm{M}$ website views per year

At $\mathrm{BMC}$, research is always in progress.

Learn more biomedcentral.com/submissions 